\title{
Digital Eco-factory as an IT Support Tool for Sustainable Manufacturing
}

\author{
Michiko Matsuda $^{1}$ and Fumihiko Kimura ${ }^{2}$ \\ ${ }^{1}$ Kanagawa Institute of Technology, Kanagawa, Japan \\ matsuda@ic.kanagawa-it.ac.jp \\ ${ }^{2}$ Hosei University, Tokyo, Japan \\ fumihiko.kimura@hosei.ac.jp
}

\begin{abstract}
A sustainable discrete manufacturing using a digital eco-factory as an IT tool has been proposed. In this paper, details of a digital eco-factory with construction methods are discussed. A digital eco-factory is a virtual factory and IT support platform on which a production scenario is examined from various viewpoints. When a digital eco-factory is used, environmental impact of the planned production scenario is examined in addition to productivity and manufacturability. A digital eco-factory is constructed on a digital factory. A digital factory is constructed on the virtual production line. Multi agent technologies can be applied to modelling an actual shop floor and its components. All components are configured as software agents. These agents are called "machine agents." Furthermore, manufactured products are also configured as software agents. These agents are called "product agents." In the digital eco-factory, there are three panels which have a user interface from each different viewpoint. The three panels are a plant panel, product panel and an environmental index panel. By using a digital eco-factory, a production system designer can do pre-assessment of the configuration of the production line and production scenario, and a factory equipment vender can show performance of his equipment.
\end{abstract}

Keywords: Production modelling, Software agent, Sustainable production planning, Virtual factory, Environmental simulation.

\section{Introduction}

A low carbon society has striven for a long time to achieve conservation of the global environment. However, the realization does not progress easily. Although mechanical products, such as cars, personal computers, mobile phones, household appliances, and daily use equipment are indispensable in everyday life, their recycle/reuse systems are still at the level of considering recycling/reuse of their material or component parts only. For society to proceed further, the recycle-based manufacturing system must be improved fundamentally from the viewpoint of sustainability. At present, manufacturing enterprises are required to optimize the service to the product user while considering the sustainability of the global environment, and it becomes usual to design the whole product life cycle before the production. At the design stage, various kinds of 
CADE(s) (CAD for Environment) are used as IT support tool. This ICT investment for the use of these tools is becoming a big defrayment. Moreover, starting with the ISO 14000 series (e.g. [1-3]) for environmental management, which was issued in 1996, the methodologies for life cycle assessment techniques are being standardized (e.g. [4]). According to the above trend, at the real manufacturing scene[5], an IT support tool with low ICT investment is strongly desired for estimating production cost and environmental impact of production plans before actual production.

To use a digital eco-factory as an IT support tool for green production planning has been proposed by the authors[6-8]. A digital eco-factory is a virtual factory and integrated IT platform on which a production scenario is simulated and examined from various viewpoints. When the proposed digital eco-factory is used, green performance of the planned production scenario is examined in addition to productivity and manufacturability at the same time with various granularities such as machine level, product level and factory level. In the future, when this digital eco-factory is available as a Web service such as Cloud service and SaaS (Software as a Service), it becomes possible to use IT support tools for sustainable manufacturing with low investment. As a first step towards the above direction, the digital eco-factory must be implemented in practice.

The detailed inside structure of a digital eco-factory is discussed and determined for a practical implementation in this paper. First, technical requirements and IT solutions for them are presented. And a conceptual structure of a digital eco-factory for discrete manufacturing is shown. Modelling of a production line for the construction of virtual factory is discussed in detail. Then, the usage and control of a digital ecofactory are explained. A digital eco-factory is operated based on the execution of virtual manufacturing. Finally, an example of trial implementation is introduced.

\section{IT Support Tool for Sustainable Manufacturing}

\subsection{Requirements for the IT Support Tool}

\subsubsection{General idea of a IT Support Tool}

The production engineer and plant manager use the IT support tool to assess and examine the production scenario before the actual execution of the production. The product designer also uses this tool to consider the production process in the product life cycle. Moreover, the manufacturing device and equipment developer use this tool to examine and show the capability and environmental efficiency of new devices and equipment. The IT support tool shows performance and environmental impact from the various view points by simulation of the input production scenario. Figure 1 shows the image of the IT support tool. This IT support tool is called "digital ecofactory." Production lines in an actual factory are modelled as a virtual factory in a digital eco-factory. Virtual manufacturing is performed according to the input scenario in the virtual factory, and its performance is watched from the product viewpoint, production line viewpoint and other viewpoints. 


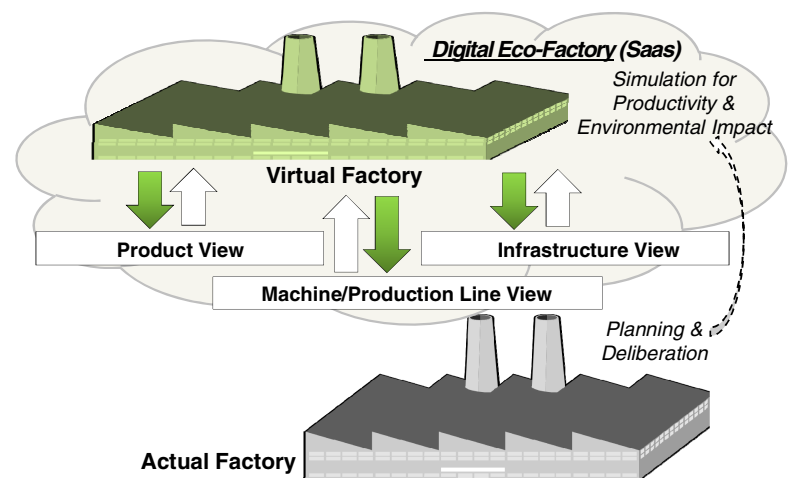

Fig. 1. General idea of an IT support tool

\subsubsection{Required Functions for the IT Support Tool}

There are functional requirements for the digital eco-factory as an IT support tool from systematic view, monitoring view and user interface view[6-7]. Following are the major functional requirements:

- easy input of production scenario such as device/equipment configuration, production schedule, process plan, manufactured product data, optimization parameters, change of schedule/plan,

- precise simulation of production scenario from the machine view, process view and product view,

- simulation which also includes added peripheral equipment such as an airconditioner to equipment which is directly used in the production.

- computation of environmental items such as the amount of raw materials and various energy intensities (ex. CO2, NOx, SOx, energy consumption) in addition to conventional items such as production costs and delivery time,

- monitoring for status of each and every process (machine), each and every product, and the system as a whole,

- and monitoring for relationships between environmental indicators and an indicator in cost-oriented conventional processes such as delivery time and production cost.

\subsection{A Digital Eco-factory as an IT Support Tool}

To fulfil the above functional requirements, the digital eco-factory must be a robust IT platform for simulation of various production scenarios, pre-assessment of various line configurations, and comparison of several production processes. Furthermore, technologies are required for the proper evaluation of each process by carefully making individual components one by one, and assessing the entire factory based on them. To implement these things on an actual IT platform, it is important to construct precise models of a production line, production process and target product including both of static properties and dynamic behaviour. In other words, the core of the digital ecofactory is a digital factory in which actual machine, production line and factory are 
mirrored. There are several previous studies about digital factory (e.g. [9-11]) in which production lines are modelled statically. Based on these result, authors proposed using multi agent technology to model factory elements statically and dynamically[12-13]. Moreover, it is proposed to construct a digital eco-factory using this agent based digital factory. The conceptual structure of the proposed digital ecofactory is shown in Figure 2.

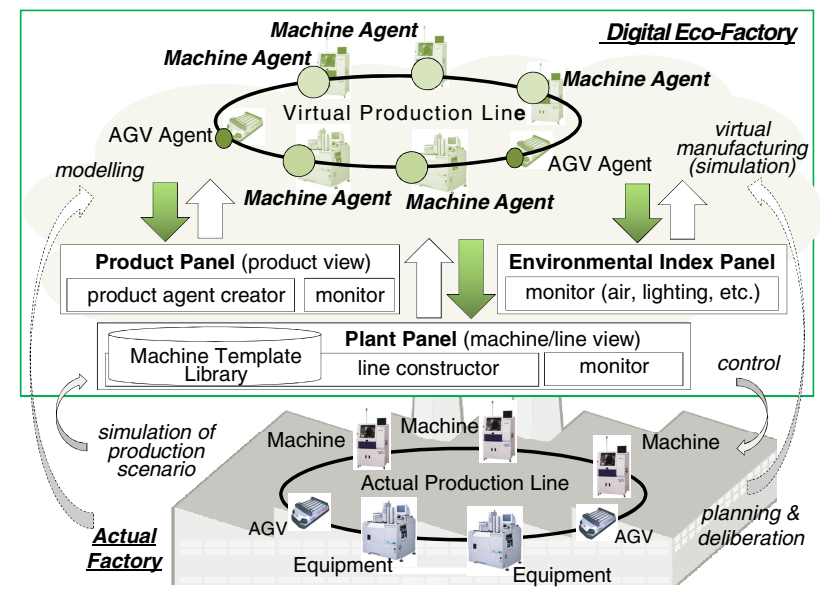

Fig. 2. Conceptual structure of the digital eco-factory

In Figure 2, the digital factory is the basis of the digital eco-factory. The digital factory is constructed on the virtual production line modelling an actual production line and its components. All components are configured as software agents. These agents are called "machine agents." In addition to machine agents, manufactured products are also configured as software agents. These agents are called "product agents." In the digital eco-factory, there are three panels which have a user interface from each viewpoint. The three panels are plant panel, product panel and environmental index panel. The operator of the digital eco-factory can input production scenario, configuration of the shop floor, control policy for the production line, energy saving policy, granularity of environmental indexes etc. through the user interface of the panels. The operator can also observe progress and results of virtual production through the user interface of the panel. The product panel controls the progression of virtual production by the creation of product agents.

\section{$3 \quad$ Modeling for Virtual Production}

\subsection{Modeling for Production Line}

\subsubsection{Machine Agent and Machine Capability Model}

A machine agent is a software agent which has its machine capability model. According to the production line configuration, machine agents are set by the plant panel. 
A machine agent simulates behaviour and activity of the manufacturing machine by referring the machine capability model. Manufacturing machines represent all of the device/equipment on the shop floor, including human operators. In other words, the machine capability model statically describes a machine's data, and a machine agent dynamically represents a machine's performance. Machine agents communicate with each other and autonomously structure a production line on the virtual shop floor.

The structure of a machine capability model is schematically shown in Figure 3. A machine capability model consists of specification data of a machine, operations which the machine can perform, knowledge on how to operate processes, required utilities such as air and light, and knowledge on how to calculate cost related items and environmental indexes. Operation data has operation orders and its own operation conditions. Operation data consists of performed operation types such as machining, screwing and bonding, using tools and jigs corresponding to the each operation, energy consumption for each single operation and other operation information such as operation method and control algorithm. The machine capability model provides the associated production line ID and its position in the line. If an associated production line ID is the same, they are in the same production line and the associated line position shows the order of machine positioning. A machine agent has its own machine capability model. The plant panel has templates for machine capability models and fulfils an adequate template when initially setting a machine agent.

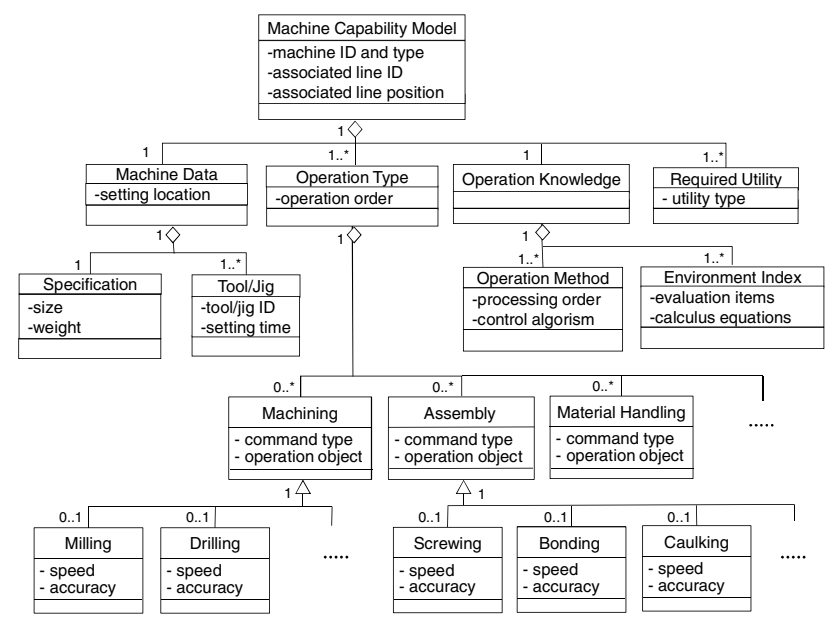

Fig. 3. Structure of a machine capability model

When setting a machine agent, the machine capability model and control rules are given. The activity diagram of a machine agent is shown in Figure 4 . When a new job is requested by the product agent, the machine agent schedules the job, puts the job in the waiting job list and generates an operation plan. In parallel, the machine agent precedes virtual operations. A machine agent fetches the job from the job list, simulates controls and operations for the job, calculates productivity data and environmental indexes, and reports them in an operating condition report. The machine capability model is referred to at every stage in a machine agent. 


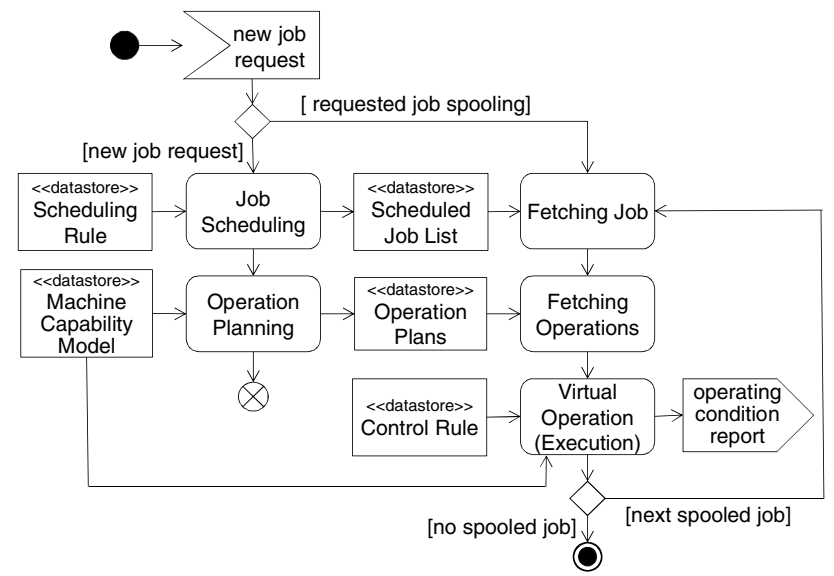

Fig. 4. Activity diagram for a machine agent

\subsubsection{Product Agent}

A product agent is a collective designation such as a workpiece agent with the workpiece data and the machining process data, and the part agent with the part data and the assembly process data. According to the production schedule, a product agent with product model and process plan data is created by the product panel. Product model and process plan data are prepared outside of a digital eco-factory using a design assist system such as a CAD/CAM system. Usually, the product model and process plan are included in a production scenario. The activity diagram of the product agent is shown in Figure 5. A product agent has a machine allocation rule, process plan for completing the product and the product model. When the production request is accepted, a product agent allocates jobs to adequate machine agents in an order according to the process plan, monitors product condition in the virtual operation by collecting productivity data and environmental data from the machine agent, and reports production status of the product.

\subsection{Production Scenario}

A reviewing production scenario is input to the digital eco-factory. Usually, a production scenario is prepared by a production engineer such as a process planner. A production scenario is validated by virtual production following the scenario. By repeatedly modifying and validating a scenario, a proper production scenario is selected from an economical point and environmental point of view. A formal structure of the production scenario is shown in Figure 6. A production scenario is constructed from product data, which is a target of the manufacturing process, which are job sequences for producing the product, and rules and methods for executing the virtual production. 


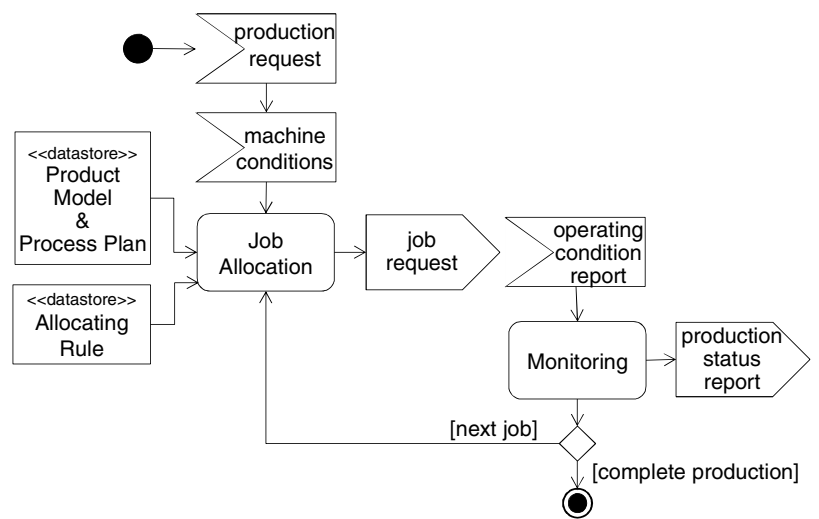

Fig. 5. Activity diagram for a product agent

Product data includes data of its component parts and workpiece data. A process consists of sub processes. A minimum sub-process is a job which is executed on some resources. There are rules and methods such as methodology and optimized parameters for production line control, dispatching rules for scheduling and theory for machine allocations $[8,13]$.

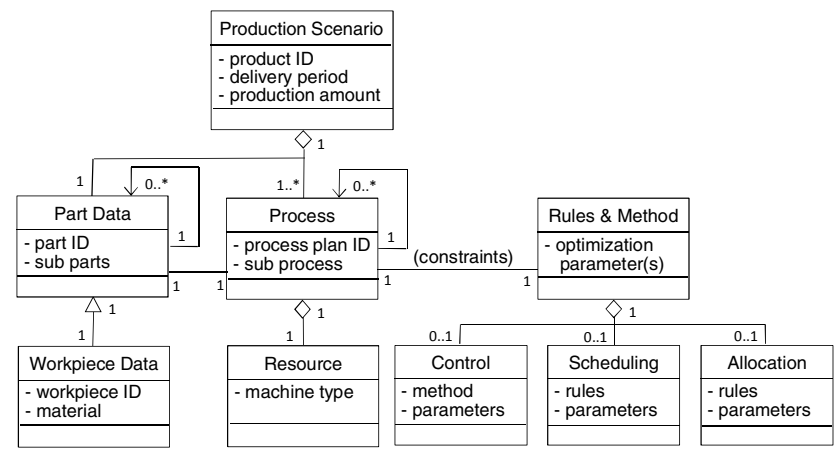

Fig. 6. Structure of a production scenario[8]

\section{$4 \quad$ A Digital Eco-factory}

\subsection{Construction of the Virtual Production Line}

A virtual production line is constructed by machine agents and product agents. A sequence diagram of a virtual manufacturing in a virtual production line is shown in Figure 7. A virtual production line configuration is given as activations of machine agents by the plant panel. According to the production scenario, the product panel creates product agents. When a product agent is created, the first step of the virtual manufacturing procedure is that a product agent requests machine status from machine agents. Depending on the reply, the product agent requests the job execution on 
the allocated machine. The machine agent replies with the estimated job starting time and the product agent confirms the job request. Furthermore, the product agent requests an AGV agent to transfer virtual things such as material, mounted parts and tools to the machine for virtual execution of the job. The machine agent proceeds with the virtual operation according to the scheduled job list in proper order. When the machine agent starts the virtual operation, the machine agent notices the starting to the product agent. During execution of the virtual operations in the machine agent, the machine agent reports the condition and status to the product agent and others. The product agent makes and sends the report to the product panel.

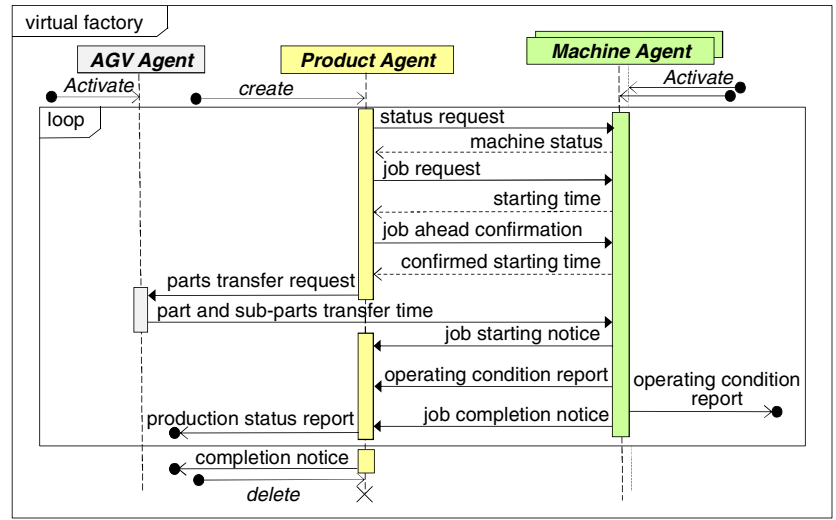

Fig. 7. Sequence diagram of a virtual production line

\subsection{Pannels for User Interfaces}

\subsubsection{Plant Panel}

The plant panel sets up the configuration of a virtual production line, and shows the operating condition and status of machines which are used to manufacture products in a virtual production line. Figure 8 shows the activity diagram of a plant panel. The configuration of the production line and details of component machines (devices and equipment) are provided from outside of the digital eco-factory by the operator. When a new machine is indicated, the plant panel sets up machine agents with a machine capability model corresponding to the input configuration by using templates of the machine capability model. On the other hand, when an already set up machine is indicated, the plant panel activates the corresponding machine agent with associated production line information. During execution of virtual production, by communicating with machine agents, the plant panel monitors the machine status on the virtual production line, collects operation condition data, productivity data and environmental data, and calculates the total of the economical and environmental index. When the configuration is changed, an operator could indicate this through deletion/generation of machine agents through the plant panel. 


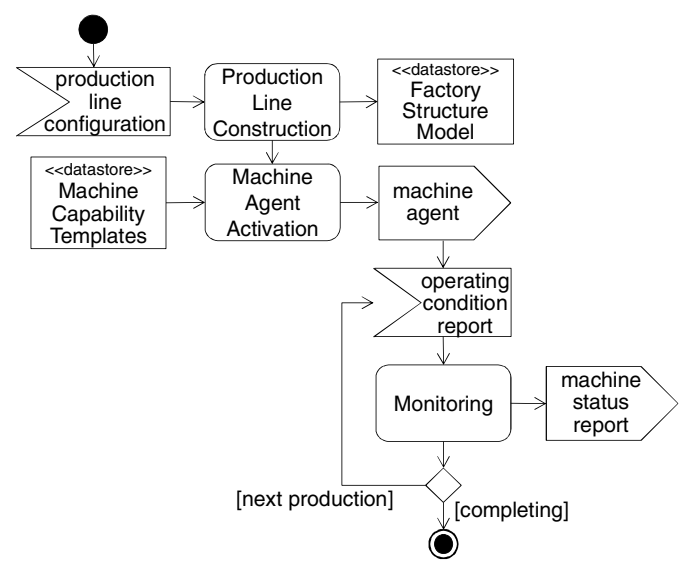

Fig. 8. Activity diagram for a plant panel

\subsubsection{Product Panel}

The product panel creates the product agent with a process model by referring to the production scenario and product model, and shows the progression and status of the manufactured product on the virtual shop floor from the productivity and environmental views. The activity diagram of the product panel is shown in Figure 9.

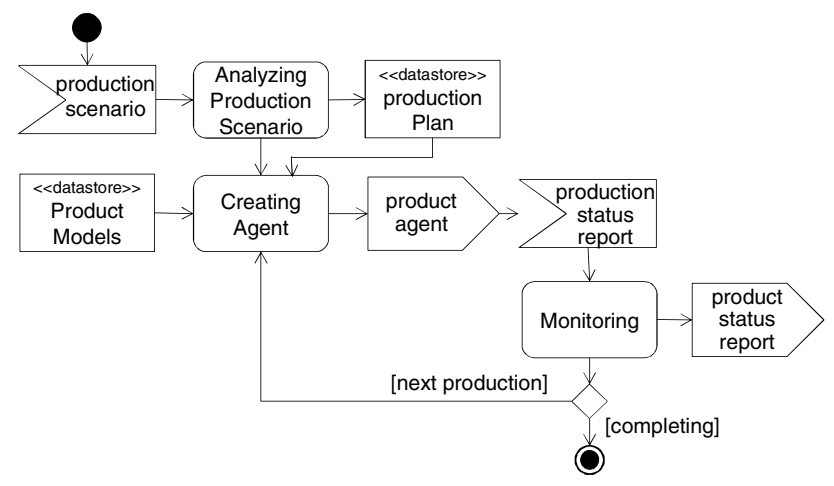

Fig. 9. Activity diagram for a product panel

At first, the product panel analyses the production scenario which includes manufactured product data such as parts structure, production amount, delivery period, and process plan, and the product panel generates the production schedule plan. According this plan, the product panel creates product agents and inputs them to the digital factory to start production for each product. As virtual production proceeds, the product panel monitors the progression and status of the products on the virtual shop floor from the productivity and environmental views. And the product panel displays the product status, collects environmental data and productivity data, calculates an environmental index by communicating with product agents and reports them. 


\subsubsection{Environmental Index Panel}

The environmental index panel shows green performance indexes such as carbon dioxide emissions and energy consumption at the machine level, production line level and plant/factory level. At the plant level, green performance indexes from plant utilities such as air compressor, air conditioning, exhaust air and lighting are also included. Figure 10 shows the activity diagram of an environmental index panel. The environmental index panel calculates green performance indexes based on the operating condition report from a machine agent by referring to the machine capability model. And the index panel generates a green performance report for each machine. This report is called the machine index report. Using this machine index report, the index panel calculates green performance indexes for production lines and produces a line index report. Then, using this line index report and utility consumptions, the index panel calculates green performance indexes of the whole plant. Utility consumptions are calculated in parallel using reported data such as power consumption and airflow volume from machine agents and referring to machine capability models.

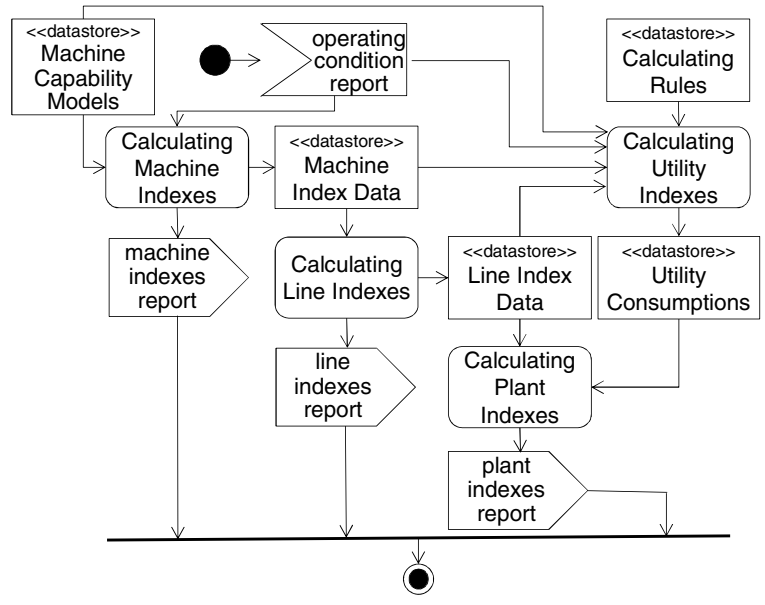

Fig. 10. Activity diagram for an environmental index panel

\section{Usage of a Digital Eco-factory}

\subsection{Green Performance Simulation}

Using the digital eco-factory, the productivity and green performance of production scenario can be simulated and evaluated. The sequence flow in the digital eco-factory is shown in Figure 11. The sequence flow of the digital factory which is the core of a digital eco-factory is shown in Figure 7. In Figure 11, relationships among the three panels and the digital factory are clarified. The production plan which indicates the workpiece/part input order to the production line and production scenarios are input to the product panel. By changing the production plan, the creation order of the product agent can be controlled. And, by changing production scenario, the job allocation to a 
machine agent by a product agent can be controlled. The production line configuration is input to the plant panel. By changing line configuration data, the activation of a machine agent through the plant panel can be controlled. As a result, various production plans, line configurations and production scenarios are easily comparable by using the digital eco-factory. Three panels monitor and report green performance simulation in the digital factory through their own view.

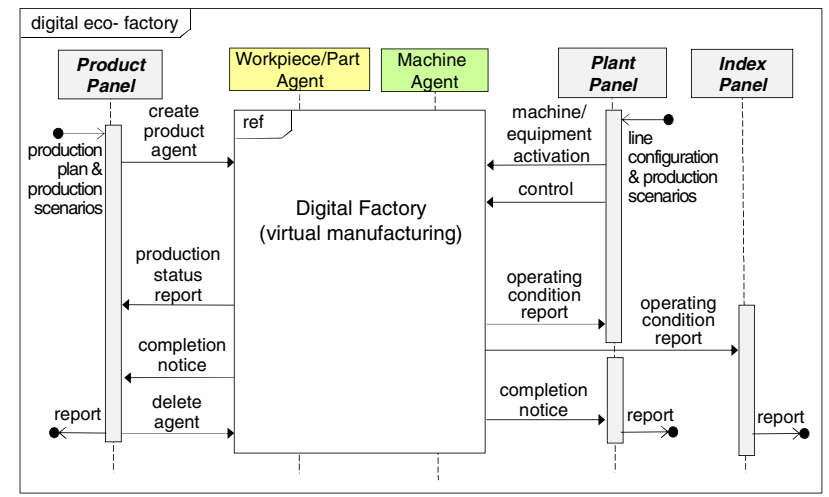

Fig. 11. Sequence diagram of a digital eco-factory

\section{$5.2 \quad$ Trial Example}

Proposed concept of digital eco-factory is applied to the PCA (Printed Circuit Assembly) line. This trial system is implemented using a commercially available multi-agent simulator "artisoc." A PCA line consists of a solder paste printing machine, three electronic part mounters, reflow furnace and testing machine. In the PCA line, processes for the above machines are proceeded in sequence, these machine's capabilities are modelled as individual machine agents due to the precise simulation. There are six types of printed boards produced, depending on the number of mounted electronic components and the temperature of the solder. When a blank PCB (Printed Circuit Board) is input to a solder paste printing machine, the production process is started. A PCB is modelled as a part agent which is one of the product agents. Figure 12 shows the modelling concept for PCA line and parts of the concrete descriptions for some the agents in "artisoc". In this example, there are two PCA lines. Figure 13 shows displays of the execution example for the virtual production of the PCA. The animation display for the condition of agents is seen at the left-upper part of Figure 13, and the window at the right-upper part is the control panel for setting production volume for each type of PCA. Power consumption of each machine on each line from the environmental view is monitored in the lower part of Figure 13. The block graph at the lower left shows power consumptions for each machine in the PCA line no.1. Power consumption of the reflow soldering oven is predominantly large. In the PCA line at the lower right, the same phenomenon could be seen. 


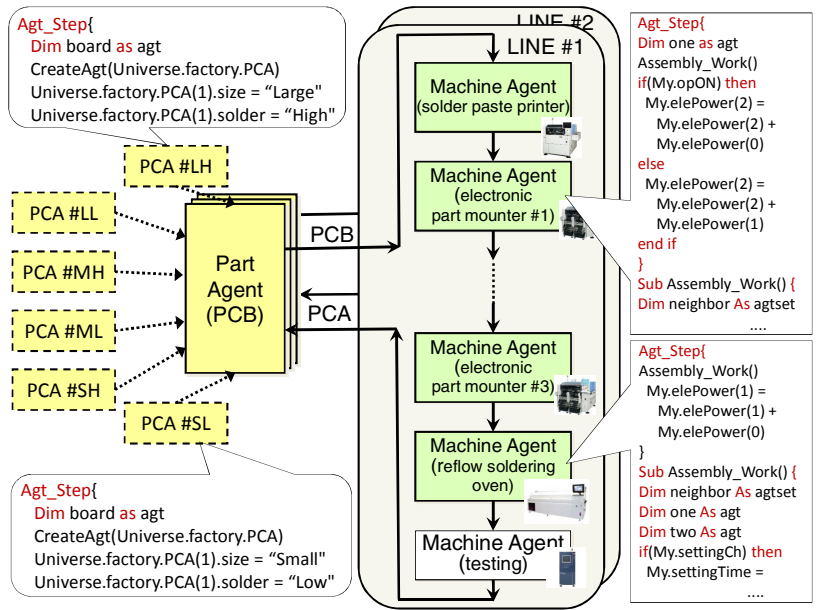

Fig. 12. Modelling of the PCA production line

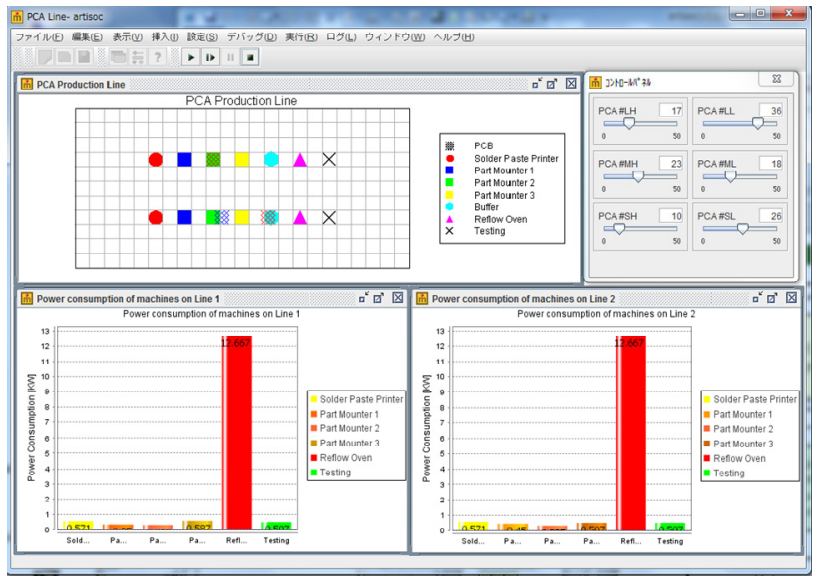

Fig. 13. Display example for the trial simulation of PCA production

\section{Conclusions}

For the practical implementation of the proposed digital eco-factory, the detailed design of the digital eco-factory is discussed in this paper. Key items are how to precisely model the production activities statically and dynamically. In this paper, it is proposed that multi agent technologies are applied for modelling of production line and production behaviour. All elements configuring the production line are implemented as software agents including manufactured products. Agents communicate with each other and autonomously construct a virtual production line. Through the virtual manufacturing in the virtual production line, environmental effects can be estimated. The small trial example shows the effectiveness of the proposed implementation method of the digital 
eco-factory. A digital eco-factory will support sustainable discrete manufacturing by virtually executing production. For future work, more trial implementations are required, and further detailed design should be generated, based on the results of trial implementations.

Acknowledgements. The authors thank members of research project titled "the digital eco factory" by FAOP (FA Open Systems Promotion Forum) in MSTC (Manufacturing Science and Technology Center), Japan for fruitful discussions and their supports. The authors are also grateful to Dr. Udo Graefe, retired from the National Research Council of Canada for his helpful assistance with the writing of this paper in English.

\section{References}

1. ISO 14001 2004. Environmental management systems - Requirements with guidance for use

2. ISO 14031 1999. Environmental management - Environmental performance evaluation Guidelines

3. ISO 14044 2006. Environmental management - Life cycle assessment - Requirements and guidelines

4. ISO FDIS 20140-1 2012 Evaluating energy efficiency and other factors of manufacturing systems that influence the environment - Part 1: Overview and fundamental principles

5. Fysikopoulos, A., Anagnostakis, D., Salonitis, K., Chryssolouris, G.: An Empirical Study of the Energy Consumption in Automotive Assembly. Procedia CIRP (Special Issue on 45th Conference on Manufacturing Systems) 3, 540-547 (2012)

6. Matsuda, M., Kimura, F.: Digital eco-factory as an IT platform for green production. In: Design for Innovative Value Towards Sustainable Society. IFIP, pp. 635-639. Springer (2011)

7. Matsuda, M., Kimura, F.: Configuration of the Digital Eco-Factory for Green Production. International Journal of Automation Technology (Special Issue on Green Manufacturing and Supply Chain) 6(3), 289-295 (2012)

8. Matsuda, M., Kimura, F.: Usage of a digital eco-factory for green production preparation. Procedia CIRP (Special Issue on 46th Conference on Manufacturing Systems) (in printing, 2013)

9. Freedman, S.: An overview of fully integrated digital manufacturing technology. In: Proc. of the 1999 Winter Simulation Conference, pp. 281-285 (1999)

10. Bley, H., Franke, C.: Integration of product design and assembly planning in the digital Factory. CIRP Annals - Manufacturing Technology 53(1), 25-30 (2004)

11. Monostori, L., Váncza, J., Kumara, S.: Agent-based systems for manufacturing. CIRP Annals-Manufacturing Technology 55(2), 697-720 (2006)

12. Matsuda, M., Sakao, N., Sudo, Y., Kasiwase, K.: Flexible and autonomous production planning directed by product agents. In: Proc. of 43rd CIRP International Conference on Manufacturing Systems, pp. 876-883 (2010)

13. Matsuda, M., Kasiwase, K., Sudo, Y.: Agent Oriented Construction of a Digital Factory for Validation of a Production Scenario. Procedia CIRP (Special Issue on 45th Conference on Manufacturing Systems), 115-120 (2012) 